\title{
Spatiotemporal Trend Analysis of Precipitation Extremes in Ho Chi Minh City, Vietnam During 1980-2017
}

\author{
Nguyen Trong Quan ${ }^{1}$ Dao Nguyen Khoi ${ }^{2,3}$ - Nguyen Xuan Hoan ${ }^{4}$. \\ Nguyen Ky Phung ${ }^{5}$ Thanh Duc Dang ${ }^{6}$
}

Accepted: 7 September 2020/Published online: 30 October 2020

(C) The Author(s) 2020

\begin{abstract}
In this study, the spatiotemporal variability of trends in extreme precipitation events in Ho Chi Minh City during the period 1980-2017 was analyzed based on several core extreme precipitation indices (Rx1day, Rx5day, CDD, CWD, R20mm, R25mm, R95p, and SDII). The nonparametric Mann-Kendall and Sen's slope methods were used to compute the statistical strength, stability, and magnitude of trends in annual rainfall, as well as the extreme precipitation indices. We found that $64 \%$ of the stations had statistically significant upward trends in yearly rainfall, with high magnitudes frequently observed in the northern and southern regions of the city. For the extreme precipitation indices, only SDII and R25mm showed dominantly significant trends. Additionally, there were increasing trends in the frequency and duration at the southern and central regions of the city during the study period. Furthermore, El Niño-Southern Oscillation and Pacific Decadal Oscillation positively correlated with the duration and negatively correlated with the intensity and
\end{abstract}

Dao Nguyen Khoi

dnkhoi@hcmus.edu.vn; dnkhoi86@gmail.com

1 Faculty of Environmental and Food Engineering, Nguyen Tat Thanh University, Ho Chi Minh City 700000, Vietnam

2 Faculty of Environment, University of Science, Ho Chi Minh City 700000, Vietnam

3 Vietnam National University, Ho Chi Minh City 700000, Vietnam

4 Ho Chi Minh City University of Food Industry, Ho Chi Minh City 700000, Vietnam

5 Institute for Computational Science and Technology, Ho Chi Minh City 700000, Vietnam

6 Engineering Systems and Design Pillar, Singapore University of Technology and Design, Tampines 487372, Singapore frequency of extreme precipitation. Thus, water management plans should be adjusted appropriately to reduce the severe impacts of precipitation extremes on communities and ecosystems.

Keywords Spatiotemporal trend - Extreme precipitation - Extreme precipitation indices $\cdot$ Ho Chi Minh City

\section{Introduction}

Precipitation has widely been recognized as a fundamental element of the hydrological cycle and a critical meteorological variable for investigating hydrometeorological processes. In particular, the spatiotemporal patterns of precipitation and precipitation-related extremes are widely considered the key factors influencing natural ecosystems and human society (Rosenzweig et al. 2002; Revadekar and Preethi 2012; IPCC 2013). Many researchers have indicated that the impacts of extreme climate events on the natural environment and human society are far outweigh the effects of normal climate conditions (Field et al. 2012; Barrett and Santos 2014; Guan et al. 2014; Mei et al. 2018). The increased precipitation extremes in terms of frequency and intensity induce natural hazards and disasters, including droughts, floods, salinity intrusion, and soil erosion, which cause huge damages on natural ecosystems and socioeconomic development (Wang et al. 2017). A global risk report developed by the World Economic Forum (WEF) highlighted that extreme weather events and disasters rank among the top three risks that have the most severe impact on human society, for example, on urban water supply and agriculture (WEF 2018). Consequently, extreme climate events, especially precipitation extremes, 
have received a high priority and concerns from scientists and governments. Thus, a comprehensive understanding of historical trends of such events is necessary to introduce climate change mitigation and adaptation plans to prepare for possible future changes.

Various studies have been carried out over the past decades to understand the behaviors of precipitation extremes on different spatiotemporal scales. On a global scale, the precipitation extremes have generally increased, especially in the Northern Hemisphere mid-latitude region (Alexander et al. 2006; Alexander 2016). Donat et al. (2016) found increasing trends of total precipitation and extremes in various regions. On a continental scale, there was an increasing trend in precipitation over Europe in the period 1951-2010 (van den Besselaar et al. 2013). In South Asia, there was also an increasing trend of most precipitation extremes during the period 1971-2000 (Sheikh et al. 2015). Endo et al. (2009) demonstrated that the intensity of precipitation extremes had dominantly upward trends in the period 1950-2000. In comparison with global and continental studies on precipitation extremes, regional studies may have more practical importance in developing adaptation and mitigation strategies to precipitation-related disasters (Li et al. 2018). Regional trends of extreme precipitation events may vary largely from place to place due to disparities in geographical and climatic features (Tan et al. 2017). For example, in the same tropical area, the frequency and intensity of extreme precipitation events show increasing trends in the Kelantan River Basin (Malaysia) (Tan et al. 2017), but this is not true for Western Thailand (Sharma and Babel 2014). Therefore, studies on regional trends of extreme precipitation events are very necessary, especially in the context of climate change.

There have been a rising number of studies on trend analysis of regional precipitation extremes in recent years (Lupikasza 2010; Gocic and Trajkovic 2013; Tian et al. 2017; Pińskwar et al. 2019). For instance, Li et al. (2018) used the Mann-Kendall test and extreme precipitation indices to investigate trends of precipitation extremes in Singapore during 1980-2013; they found that the frequency and intensity of precipitation extremes had significant rises. Tan et al. (2017) investigated the spatiotemporal patterns of precipitation extremes in the Kelantan River Basin in Malaysia during 1985-2014 using 14 extreme precipitation indices and Mann-Kendall and Sen trend tests; they found that the intensity and frequency of the precipitation extremes had upward trends. Another study by Supari et al. (2017) for the period 1983-2012 showed that insignificant trends with low spatial consistency of precipitation occurred over Indonesia. In the aforementioned studies, extreme precipitation indices as recommended by the Expert Team on Climate Change Detection and Indices (ETCCDI) and parametric and non- parametric statistic tests (for example, Mann-Kendall test, Sen's slope, and Pettit tests) were applied to detect the trends in precipitation extremes in different temporal scales. Additionally, this approach has been broadly used for studies on trend analysis of climatology in recent years (Wang et al. 2016; Zhang et al. 2017).

Vietnam, a tropical country in Southeast Asia, is highly vulnerable to adverse impacts of climate change and climate extremes (IMHEN and UNDP 2015). In the period 1997-2016, Vietnam suffered approximately 216 extreme climate events, which caused an annual economic loss of approximately $0.55 \%$ of gross domestic product (GDP)) (Eckstein et al. 2017). Only a few studies have been conducted to analyze trends in extreme precipitation events in Vietnam. Ho et al. (2011) found a downward trend in heavy precipitation events in most regions of Vietnam, except for the Red River Delta and North Central Vietnam during 1961-2007. Ngo-Duc (2014) reported a downward trend in the precipitation extremes in northern coast and an upward trend in southern coast of Vietnam from 1961 to 2011. The two macro climate extreme studies focused on the trends in precipitation extremes at the country level. However, there is a lack of analysis on meso climate extremes, where local geophysical phenomena and geographical features may influence precipitation characteristics. Therefore, basin-wide or provincial-scale studies are essential to enhance the understanding on the variation of local precipitation extremes and to help local governments gain scientific information for disaster risk management. In addition, climate variability in Vietnam is modulated by El Niño Southern Oscillation (ENSO) and Pacific Decadal Oscillation (PDO) (Nguyen et al. 2014; D'Arrigo and Ummenhofer 2015; Gobin et al. 2016). The two phenomena are linked to significant anomalies in precipitation across Vietnam (Binh et al. 2019). However, the relationship between precipitation extremes and large-scale patterns of climate variability, that is, global mean temperature, ENSO, and PDO, in Vietnam is not well understood.

The objectives of this study were to detect the spatiotemporal trends of extreme precipitation events and their correlations with large-scale climate circulation patterns in the period 1980-2017. Ho Chi Minh City (HCMC) was selected as the case study for this investigation to help us understand rainfall variability in megacities over the last few decades. Additionally, HCMC was ranked 6th of 51 "extreme risk" cities with the highest vulnerability to climate change and weather extremes (UN 2014). The results obtained from the present study may provide scientific references for disaster risk reduction in HCMC in the context of climate change. 


\section{Study Area and Data}

This section presents the brief information about the study area and data used in this study.

\subsection{Study Area}

Ho Chi Minh City is the largest and most populous city in southern Vietnam. It is also the most significant economic hub in the country, contributing approximately $21 \%$ of Vietnam's overall GDP (HCMC-SO 2017). The total area of HCMC is approximately $2095 \mathrm{~km}^{2}$, and the population was 8.4 million in 2016 with the highest population density of 4029 people per $\mathrm{km}^{2}$ in Vietnam (HCMC-SO 2017) (Fig. 1). Approximately $50 \%$ of its area has a low elevation varying from 0 to $1.5 \mathrm{~m}$ above the mean sea level; thus, it is very vulnerable to floods if the water level reaches $2.0 \mathrm{~m}$ based on future climate change scenarios (WB 2010).

Ho Chi Minh City has a tropical monsoon climate with two distinct dry and wet seasons. The annual rainfall varies between 1700 and $2300 \mathrm{~mm}$, and the annual average temperature ranges from 27 to $28^{\circ} \mathrm{C}$ (HCMC-SO 2017). The city is frequently affected by floods from upstream rivers, high tides, and the increasing trend of extreme rainfalls due to the impact of climate change. The estimated cost for mitigation and adaptation is expected to be highest in the East Asia region (WB 2010; van Leeuwen

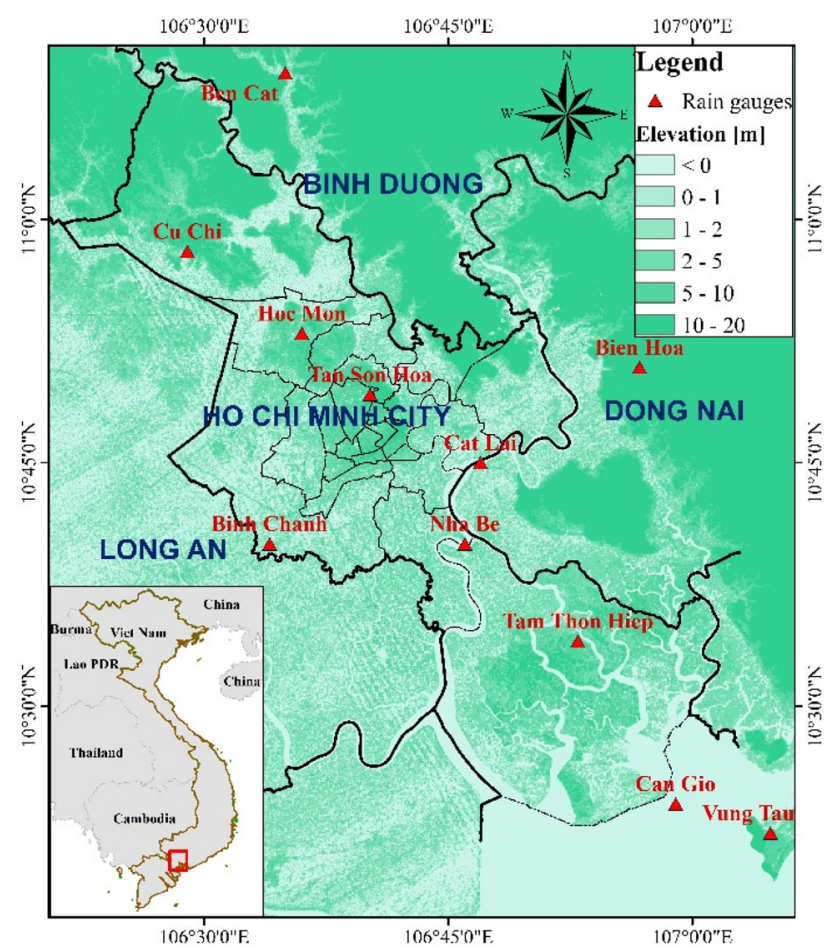

Fig. 1 Map of Ho Chi Minh City and locations of 11 rain gauges used in this study et al. 2016). Therefore, more comprehensive research in this area on these topics is encouraged by the city government.

\subsection{Data}

In this study, observed daily precipitation data recorded from 11 rain gauges in HCMC and its neighboring areas during the period 1980-2017 were provided by the HydroMeteorological Data Center of Vietnam. The locations of these stations are illustrated in Fig. 1. These rain gauges were selected because they can provide complete daily precipitation data series in the period 1980-2017 and they have sufficient density and spatial coverage across the study area, which are very essential to analyze extreme events extensively.

To guarantee the reliability and consistency of rainfall data before calculating the extreme precipitation indices and conducting the trend analysis, data quality control method and homogeneity assessment were applied. Data quality and homogeneity tests were performed by using the RClimDex package (Wang and Feng 2004) and RHtest package (Wang and Feng 2013), which were approved and recommended by the World Meteorology Organization (WMO) for meteorological data processing and analysis of extreme climate indices (Tian et al. 2017).

Additionally, three sets of time series data of large-scale patterns of atmospheric and ocean circulation, including global mean temperature, ENSO, and PDO downloaded from the website of the National Oceanic and Atmospheric Administration Earth System Research Laboratory (NOAAESRL), ${ }^{1}$ were used to investigate the possible impacts of large-scale atmospheric and ocean circulation patterns on the precipitation extremes in HCMC.

\section{Methodology}

This section presents the methods used in this study to analyze the spatiotemporal trends of extreme precipitation.

\subsection{Precipitation Extreme Indices}

To identify and estimate climate extremes (for example, temperature and precipitation), a set of 27 extreme climate indices computed from daily temperature and precipitation data series has been developed and is highly recommended by the Expert Team on Climate Change Detection and Indices (ETCCDI) (Karl et al. 1999; Peterson et al. 2001). There are many published studies using these recommended indices in analyzing climate extremes (van den

\footnotetext{
${ }^{1}$ https://www.esrl.noaa.gov/psd/data/climateindices/list/.
} 
Besselaar et al. 2013; Sheikh et al. 2015; Tian et al. 2017; Wang et al. 2017; Li et al. 2018). To provide useful information for the extreme precipitation analysis in HCMC, eight extreme precipitation indices were chosen for this study (Table 1) to consider three major attributes of extreme events, namely, intensity, frequency, and duration. All these indices were directly derived from the observed daily precipitation data of 11 rain gauges in HCMC using the RClimDex package (Wang and Feng 2004).

\subsection{Descriptive Statistics}

Prior to analyzing the extreme precipitation indices, it is crucial to perform a preliminary study on annual and seasonal daily precipitation data by using descriptive statistics, namely, minimum, maximum, median, and mean values, and standard deviation (STD), coefficient of variance (CV), kurtosis, and skewness. These statistics would provide an initial evaluation of the dispersion and distribution of the data series.

To analyze the temporal distribution of precipitation over time, the precipitation concentration index (PCI) (Oliver 1980) was used. The PCI values were calculated on an annual scale according to the equation below:

$\mathrm{PCI}_{\text {annual }}=\frac{\sum_{i=1}^{12} p_{i}^{2}}{\left(\sum_{i=1}^{12} p_{i}^{2}\right)^{2}} \times 100$

where $p_{i}$ is the rainfall amount of month $i$. A classification of PCI values was proposed by Oliver (1980), where values of less than 10 represent a uniform monthly distribution of rainfall (that is, low precipitation concentration), values between 11 and 15 denote moderate concentrations, values ranging from 16 to 20 indicate high concentrations, and those above 21 express very high concentrations of precipitation.

\subsection{Trend Analysis}

The widely used method for analyzing the trends of extreme precipitation is the non-parametric Mann-Kendal test. Statistical significance of trends in precipitation extremes is determined using the method proposed by Lupikasza (2010).

\subsubsection{Mann-Kendall Test}

In the climatic and hydrologic fields, trend analysis is among the most popular techniques for detecting underlying patterns of tendencies in time series. One of the wellknown trend tests is the non-parametric Mann-Kendall test (Mann 1945; Kendall 1955), which only requires data to be independent and randomly ordered, that is, no serial correlations exist among the observations. This technique is recommended by WMO as an advantageous method to test the significant monotonic trends in hydrometeorological time series and has been widely applied in detecting the significance of trends in hydrometeorological extremes (Tan et al. 2017; Ahmad et al. 2018; Li et al. 2018). The Sen's slope estimator has been applied to estimate the magnitudes of the trends (Sen 1968).

The existence of serial autocorrelation in observed hydrometeorological data would affect the detection of deterministic trends in the data series or increase the rejection of a null hypothesis of no trend (von Storch 1995). Therefore, it is necessary to conduct an intermediate step called the pre-whitening process of data series for acquiring correct trends. In this study, trend-free prewhitening (TF-PW) was applied for pre-whitening the observed data series before trend analysis. This method is a useful tool for reducing the serial autocorrelation of hydrometeorological data (Hamed 2009). The detailed procedure of this approach was outlined by Gocic and Trajkovic (2013).

\subsubsection{Trend Percentage and Stability}

Generally, trend test results are strongly influenced by the investigated time periods; thus, it has been suggested to analyze long-term persistence when assessing the significance of trends in hydrometeorological time series (Lupikasza 2010; Wu et al. 2014). In order to detect the longterm persistence on the decadal scale or longer, the 20-year, 25-year, or 30-year moving period is often used. In this study, the statistical significance of the trends of each of the extreme precipitation indices was determined over each of the 25-year moving periods during 19802017. Furthermore, for the spatial analysis of the trend significance, a station was considered to have a dominantly increasing (or decreasing) trend if the number of 25-year moving periods with significant increasing (or decreasing) trends was higher than the number of significant decreasing (or increasing) trends.

The strength of the statistically significant trends was classified by the significance level ( $p$ value) with the following categories: very strong trend: $p$-value $\leq 0.05$; strong trend: $0.05<p$-value $\leq 0.1$; weak trend: $0.1<p$-value $\leq 0.2$; insignificant trend: $p$-value $>0.2$ (Wu et al. 2014). The percentage of statistically significant trends for every extreme precipitation index was calculated according to the following equation:

$m_{j}=\frac{N_{p j}}{N_{\mathrm{S}} \times K} \times 100 \%$

where $m_{j}$ is the percentage of the specific type of trend strength for a certain extreme index $j, N_{\mathrm{S}}$ is the total 
Table 1 List of the eight extreme precipitation indices used in this study

\begin{tabular}{|c|c|c|c|c|}
\hline Type & Indices & Name & Definition & Unit \\
\hline \multirow[t]{4}{*}{ Intensity indices } & RX1day & Max 1-day precipitation amount & Monthly maximum 1-day precipitation & $\mathrm{mm}$ \\
\hline & RX5day & Max 5-day precipitation amount & Monthly maximum 5-day precipitation & $\mathrm{mm}$ \\
\hline & R95p & Very wet days & Annual total precipitation when precipitation $>95$ th percentile & $\mathrm{mm}$ \\
\hline & SDII & Simple daily intensity index & Annual total precipitation divided by the number of wet days & $\mathrm{mm} /$ day \\
\hline \multirow{2}{*}{$\begin{array}{l}\text { Frequency } \\
\text { indices }\end{array}$} & $\mathrm{R} 20 \mathrm{~mm}$ & Number of heavy precipitation days & Annual count of days when precipitation $\geq 20 \mathrm{~mm}$ & days \\
\hline & $\mathrm{R} 25 \mathrm{~mm}$ & $\begin{array}{l}\text { Number of very heavy precipitation } \\
\text { days }\end{array}$ & Annual count of days when precipitation $\geq 25 \mathrm{~mm}$ & days \\
\hline \multirow[t]{2}{*}{ Duration indices } & CDD & Consecutive dry days & $\begin{array}{l}\text { Maximum number of consecutive days with precipitation }< \\
1 \mathrm{~mm}\end{array}$ & days \\
\hline & CWD & Consecutive wet days & $\begin{array}{l}\text { Maximum number of consecutive days with precipitation } \geq \\
1 \mathrm{~mm}\end{array}$ & days \\
\hline
\end{tabular}

number of stations, $K$ is the total number of 25-year moving periods, and $N_{p j}$ is the number of the specific type of trend strength.

Then, the stability of trends was calculated as the percentage of the number of 25-year moving periods with statistically significant trends at the significance level of 0.2 with respect to the total number of 25 -year moving periods. This method simplifies the evaluation of the stability of trends direction in the long-term period (Wu et al. 2014). The equation for calculating the stability of the significant trends along with the specific direction (upward or downward) is as follows:

$S_{i j}=\frac{K_{1 i j}+K_{2 i j}+K_{3 i j}}{K}$

where $S_{i j}$ is the trend stability at station $i$ for extreme index $j, K$ is the total number of 25-year moving periods, and $K_{1 i j}$, $K_{2 i j}$, and $K_{3 i j}$ are the number of 25-year moving periods that have very strong, strong, and weak trends at station $i$ for index $j$, respectively. The detailed description of the equations for determining the trend significance and stability could be found in the studies by Wu et al. (2014) and Lupikasza (2010). According to Lupikasza (2010), the suggested classification of trend stability is as follows: unstable trend: $0 \% \leq S \leq 15 \%$; poor trend: $15 \% \leq S \leq 25 \%$; stable trend: $25 \% \leq S \leq 50 \%$; strongly stable trend: $50 \% \leq S \leq$ $75 \%$; and very strongly stable trend: $S \geq 75 \%$.

Finally, the Sen's slope estimator method was applied to calculate the trend magnitudes of each of the 25-year moving periods during 1980-2017 at every station for every extreme precipitation index. Subsequently, the averaged quantities were computed by taking the arithmetic average of the trend magnitude values for all 25-year moving periods at each station and each respective extreme index during the study period 1980-2017.

\subsection{Spatial Interpolation}

The spatial distribution of extreme precipitation indices was generated using inverse distance weighting (IDW). This method was selected for this study because it has been broadly applied in spatial interpolation applications of precipitation data (Hadi and Tombul 2018; Cooper 2019). The fundamental assumption in the IDW method is that the interpolated points are the most affected by the nearest points and the least affected by the most distant points.

\section{Results and Discussion}

This section presents trend analysis results for precipitation extremes and discusses these results in relation to similar studies.

\subsection{Statistical Characteristics and Annual Precipitation Trends}

The areas with lower rainfall amount presented higher rainfall variability. The mean annual precipitation in the study area ranged from $1043 \mathrm{~mm}$ in the southeastern region (Can Gio) to $1930 \mathrm{~mm}$ in the central area (Tan Son Hoa), and the standard deviation varied between $240 \mathrm{~mm}$ (Tam Thon Hiep) and $472 \mathrm{~mm}$ (Nha Be). In this case study, the skewness values fluctuated between -0.97 and 1.10 and increased from the northwestern to the southeastern parts of the city. Most of the stations in HCMC had a positively skewed distribution of annual rainfall data and high skewness values concentrated in the city center and the range of kurtosis value of yearly precipitation data series at the 11 rain stations ranged between -1.39 and 2.86 . In particular, the negative values of kurtosis were located in the northwestern and southeastern parts of the city, and the 
positive values were detected in the central area. With the high positive values of skewness and kurtosis, the distribution of data tended to be right skewed and had heavy tails or outliers; in other words, extreme rainfall events are more likely to occur in the central region of HCMC (including Binh Chanh, Cat Lai, Nha Be, and Tan Son Hoa) than in the northwestern and southeastern areas.

Precipitation concentration index values showed a uniform pattern over the study area, ranging between 14.96 and 18.25 , which demonstrated a moderate precipitation concentration. There was a north (lower) to south (higher) gradient in the average annual PCI values with the minimum and maximum yearly $\mathrm{PCI}$ values at $\mathrm{Cu} \mathrm{Chi}$ and $\mathrm{Can}$ Gio, respectively. In terms of the variability of annual precipitation, the CV values fluctuated between 0.14 and 0.35 , with lower values found in the center of the city and higher values in the northwestern and southeastern sides.

Lag-1 autocorrelation coefficients of annual rainfall data series during the period 1980-2017 were calculated and the results indicate that the annual rainfall data series at $\mathrm{Hoc}$ Mon, Cat Lai, Can Gio, and Bien Hoa Stations had significant serial correlations. Thus, those stations were selected for application of the TF-PW technique to remove the influence of autocorrelation before applying the MannKendall test. Results from the Mann-Kendall trend tests show that the increase in annual rainfall amounts was the dominant and significant trends. Increasing patterns were detected at Hoc Mon, Can Gio, Bien Hoa, and Vung Tau Stations $(Z>0$ and $p$-values at the 5\% significance level). High magnitudes of trends were found outside the central part of the city. The most remarkable magnitude was $18.68 \mathrm{~mm} /$ year at Can Gio in the southeastern area and the second highest value was $12.75 \mathrm{~mm} /$ year at Hoc Mon in the northwestern area. On the annual scale, only the Vung Tau Station showed a significant decreasing trend at $6.85 \mathrm{~mm} /$ year.

\subsection{Spatiotemporal Analysis of Extreme Precipitation Indices}

This section presents the temporal variability results of extreme precipitation, followed by the spatial analysis results.

\subsubsection{Temporal Distribution of Spatially Averaged Extreme Precipitation Indices}

To obtain an overview of the trends in the extreme precipitation indices during the period 1980-2017 over the entire study area, the areal mean values of each index were calculated by averaging the respective annual extreme values computed for the 11 stations. We found that there was no significant trend for most of the indices except for
SDII and CDD. In particular, the RX1day, R20mm, $\mathrm{R} 25 \mathrm{~mm}, \mathrm{CWD}$, and R95p had increasing trends, while RX5day exhibited a decreasing trend (Fig. 2); however, these trends were insignificant. In contrast, the SDII index showed a very strongly significant downtrend, with a decreasing magnitude of 0.11 unit per year; CDD presented a weakly decreasing but strongly stable trend with a magnitude of 1.22 units per year.

\subsubsection{Spatial Distribution of Temporally Averaged Extreme Precipitation Indices}

Except for the significant differences in spatial distribution between CDD and CWD indices due to their negative correlation, the spatial distribution of the remaining indices illustrated a relative similarity, with higher values observed in the central region and lower values found in the northern and southern parts of the city (Fig. 3).

The variant range of average CDD was between 82.0 and 120.3 days, with the highest value at Can Gio Station and the lowest at Tan Son Hoa Station. Longer CDD were observed in the northwestern and southeastern parts of the city, whereas shorter durations were detected in the central region. On the contrary, the number of CWD showed an increasing trend in most of the central region (except for Cat Lai Station) and tended to decrease in the northwestern and southeastern parts of the city. The CWD values ranged from 6.6 to 10.2 days.

For the $\mathrm{R} 20 \mathrm{~mm}$ and $\mathrm{R} 25 \mathrm{~mm}$ indices, there were no remarkable differences between the spatial distributions of the two indices over the study area. The values of R20mm varied between 22.3 and 53.5 days, and $\mathrm{R} 25 \mathrm{~mm}$ fluctuated from 11.9 to 44.2 days. Both R20mm and R25mm presented a west-to-east increasing gradient with the highest value observed in the eastern side of the central area (Cat Lai). In terms of RX1day and RX5day, the spatial patterns of these indices were similar to those for R20mm and $\mathrm{R} 25 \mathrm{~mm}$. Specifically, the values of the indices increased from the western to the eastern parts of the city. Lower values of RX1day and RX5day were observed in the northwestern and southeastern regions while high values were found in the central region. The mean values of RX1day ranged between 69.7 and $114.2 \mathrm{~mm}$, and the values of RX5day varied between 138.5-232.0 mm.

Regarding the amount of extreme precipitation, the spatial variability of R95p presented similar behavior with that of RX1day. The mean values of R95p ranged from $288.7 \mathrm{~mm}$ (Can Gio) to $464.2 \mathrm{~mm}$ (Tan Son Hoa), and the central part of the city had high values (between 350 and $475 \mathrm{~mm}$ ) while the northwestern and southeastern regions had lower values of less than $375 \mathrm{~mm}$. For SDII, the spatial patterns were also comparable to that of RX5day. There was a west-to-east increasing gradient of rainfall intensity. 


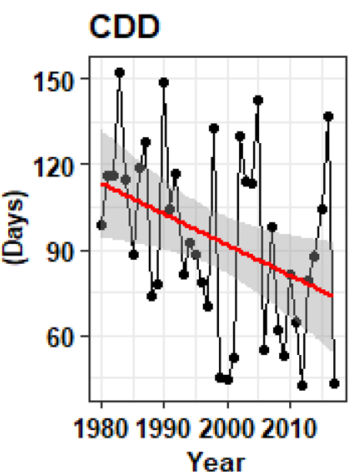

R20mm

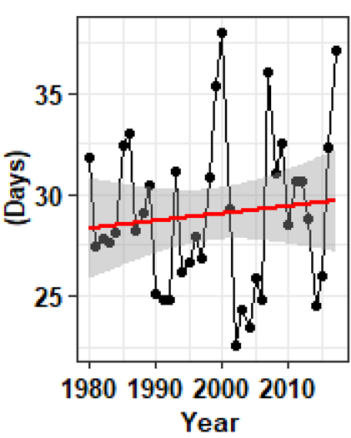

CWD

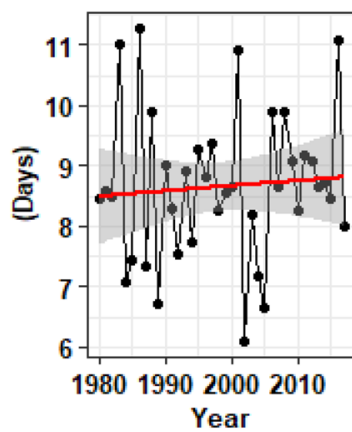

R25mm

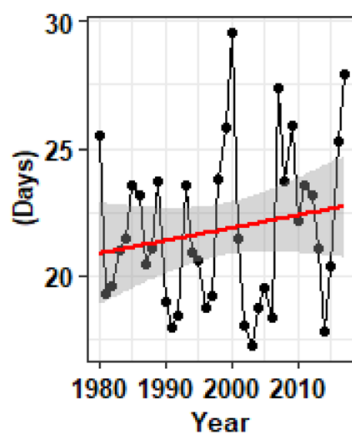

Fig. 2 Temporal variations of the spatially averaged extreme precipitation indices in the period 1980-2017. The black solid line indicates the areal average values of the 11 stations. The black dotted line indicates the average level and the red line shows the trends. RX1day: Max 1-day precipitation amount; RX5day: Max 5-day

The results indicate that the mean values of SDII in most regions of the city varied between 14 and $18 \mathrm{~mm} / \mathrm{day}$, excluding the small part of the central region (surrounding Cat Lai Station), and the highest average value of precipitation intensity was $31.3 \mathrm{~mm} /$ day.

\subsection{Trend Analysis of Extreme Precipitation Indices}

Regarding the trend analysis results for extreme precipitation, the trend strength, stability, and magnitude are presented as follows.

\subsubsection{Spatiotemporal Distribution of Trend Strengths in Extreme Precipitation Indices}

There were significant upward trends in 5 out of 8 extreme precipitation indices during the period 1980-2017. An overview is showed in Fig. 4. The prominent significant downward trends were found in SDII, R20mm, and CDD, with the highest total percentage of decreasing trends observed in SDII at $54.55 \%$ (including $43.51 \%$ of very strong downward trends). These trends indicate that the duration and amount of extreme precipitation tended to
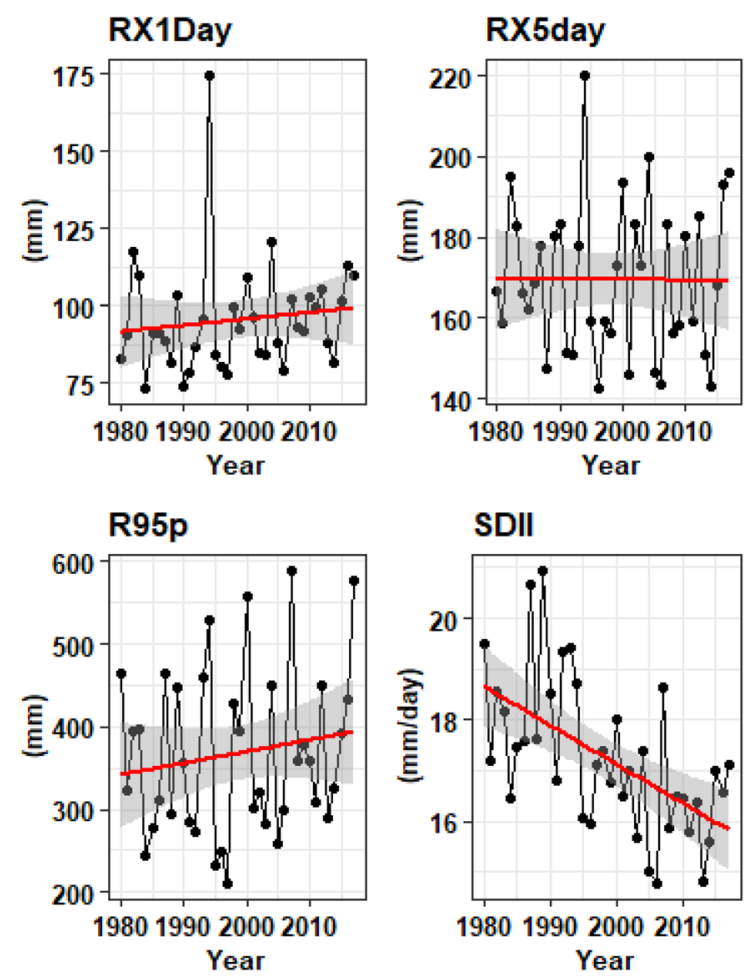

precipitation amount; R95p: Very wet days; SDII: Simple daily intensity index; R20mm: Number of heavy precipitation days; R25mm: Number of very heavy precipitation days; CDD: Consecutive dry days; CWD: Consecutive wet days

increase while their average intensity had decreased in the period 1980-2017 over the entire study area.

When considering all types of trend strengths, statistically insignificant trends were the most frequent type in most parts of the study area (67\% of the stations) (Fig. 4). There were significantly decreasing trends of $20 \%$ at the stations (comprising $15 \%$ of very strong and $5 \%$ of weak trends) and considerably increasing trends of $13 \%$ at the stations (10\% of very strong, $1 \%$ of strong, and $2 \%$ of weak trends). In general, strong and very strong trends in either downward or upward direction were observed in the northern and southern sides of the city. Notably, RX1day, RX5day, and R95p frequently had very strong upward trends at Can Gio Station and very strong downward trend at $\mathrm{Cu}$ Chi Station. For R20mm and $\mathrm{R} 25 \mathrm{~mm}$, there were small differences in the spatial distribution of trends over the study area. In particular, more significantly upward trends were observed in $\mathrm{R} 25 \mathrm{~mm}$ than those of R20 mm, especially in the central and southern regions. For CDD and CWD, a negative correlation in the spatial distribution of trends over the study area was observed. Insignificant trends were observed for CDD at most of the stations over the study area, but CWD had decreasing trends in some parts of the central region (Tan Son Hoa and Cat Lai). For 

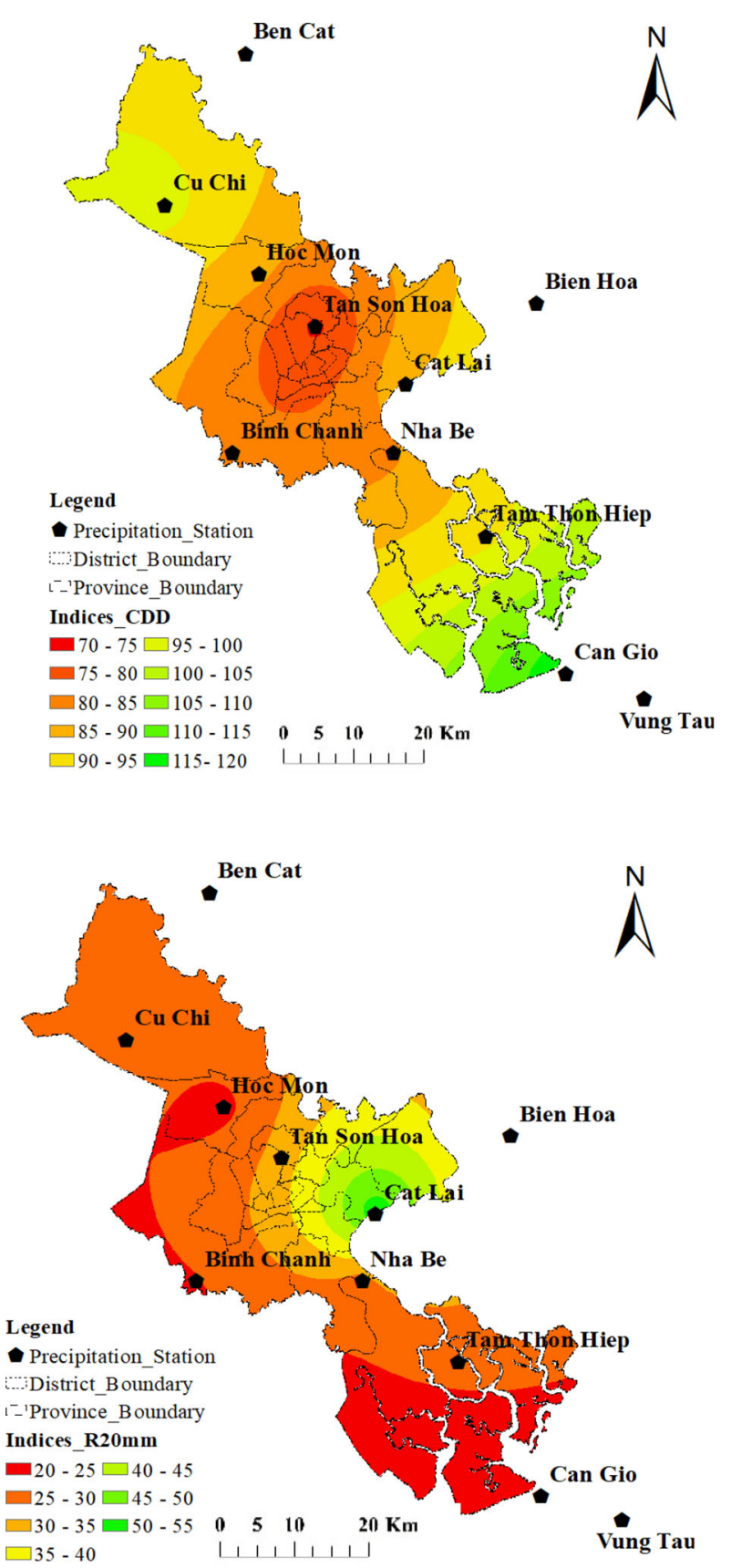

Fig. 3 Spatial distribution of extreme precipitation indices during the period 1980-2017 in Ho Chi Minh City. RX1day: Max 1-day precipitation amount; RX5day: Max 5-day precipitation amount; R95p: Very wet days; SDII: Simple daily intensity index; R20mm:

SDII, strong downward trends were found in 6 out of 11 stations, which possibly indicate a decreasing tendency in the intensity of extreme precipitation.

In general, considering all types of significant trends in the extreme precipitation indices, the tendency of the amount and duration of precipitation extremes generally increased in the southern part of HCMC and decreased in the northern and central parts during the period 1980-2017.
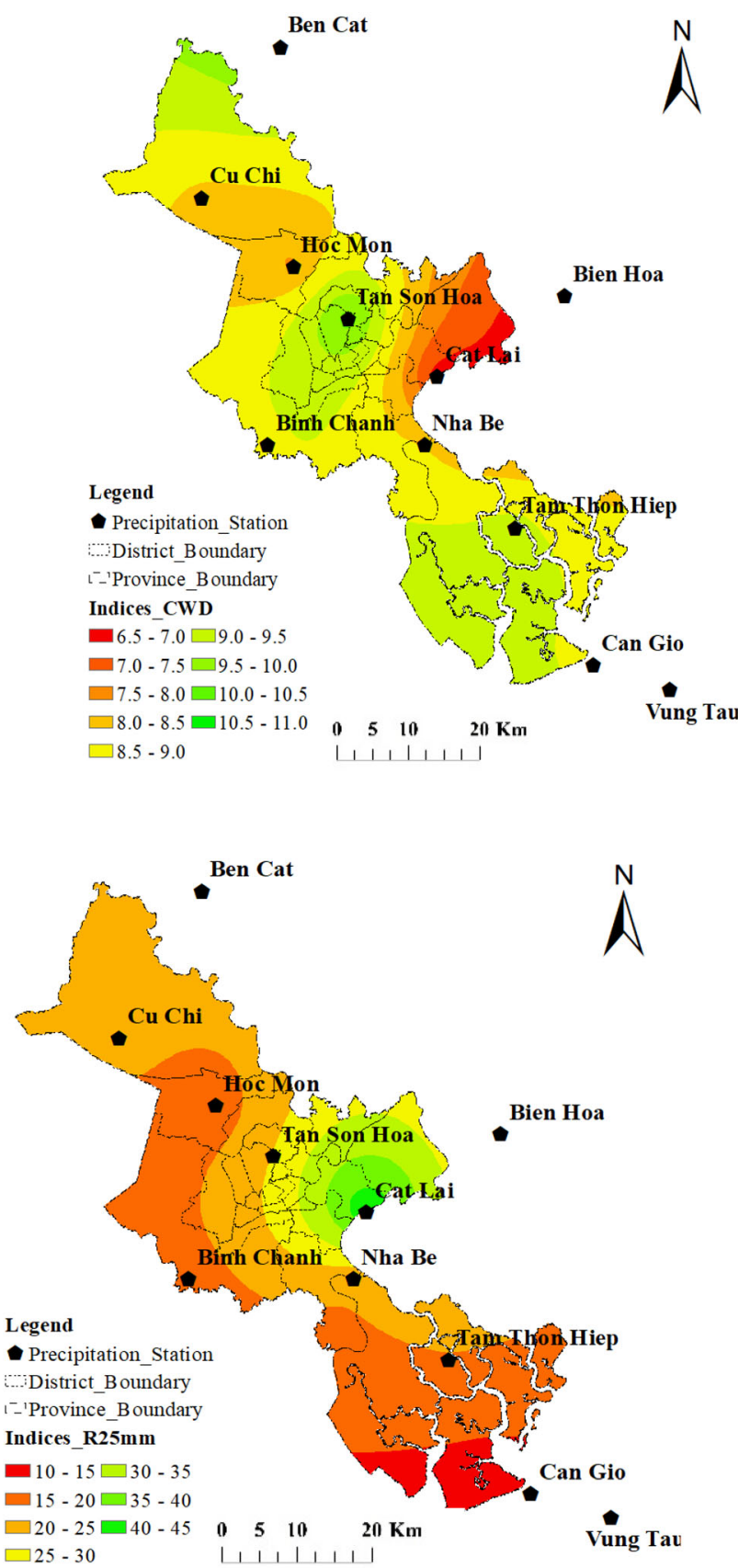

Number of heavy precipitation days; R25mm: Number of very heavy precipitation days; CDD: Consecutive dry days; CWD: Consecutive wet days

The intensity of extreme events tended to decline in most parts of the study area.

\subsubsection{Stability of Trends in Extreme Precipitation Indices}

Stable trends (66\% of the stations) were more frequently observed in the extreme precipitation indices than unstable patterns (34\% of the stations) during the study period in 

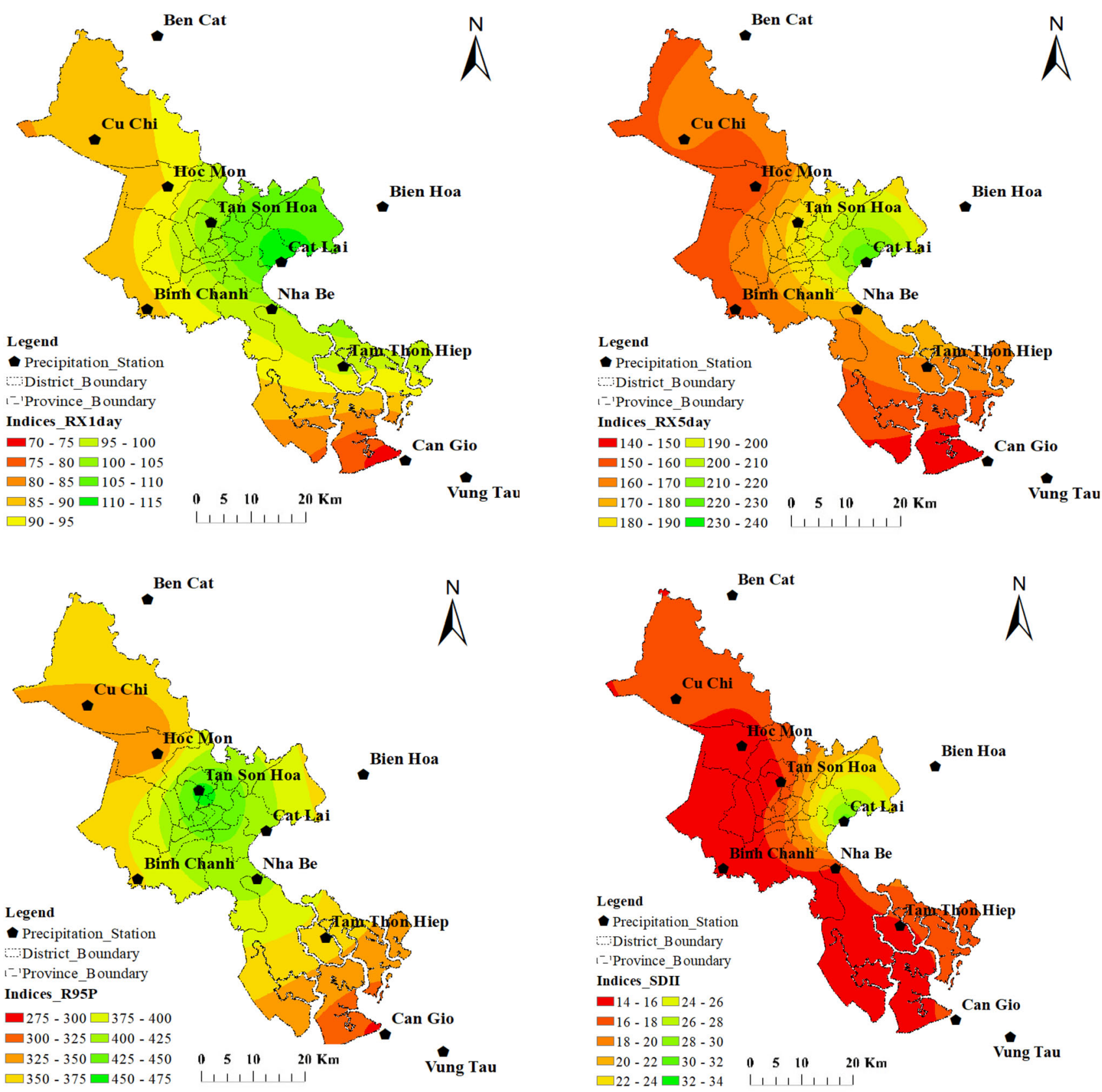

Fig. 3 continued

HCMC (Table 2). Even though significantly increasing trends less frequently appeared than significantly decreasing trends as mentioned above, the increasing trends were more stable than the decreasing trends with $6 \%$ and $3 \%$ of the stations higher with and without counting poorly stable trends, respectively. Moreover, strong and very strong stability $(T \geq 50 \%)$ were the most frequent observations for downward trends (13\% of the stations for both criteria of stability), whereas stable stability values $(25 \% \leq$
$T \leq 50 \%$ ) were mainly found in the uptrends at $12 \%$ of the stations.

Figure 5 illustrates the spatial interpolation results of stability of trends in extreme precipitation indices based on the calculation results at the 11 rain stations. Generally, there was a distinctive stability of trends regarding spatial patterns and unstable trends $(0 \% \leq T \leq 25 \%)$ were observed frequently in the central region of HCMC. Regarding each extreme precipitation index, the unstable trends $(18-55 \%$ of the stations) dominated in the study area, especially in 
Fig. 4 Percentages of trend strengths in extreme precipitation indices during the 1980-2017 period in Ho Chi Minh City. RX1day: Max 1-day precipitation amount; RX5day: Max 5-day precipitation amount; R95p: Very wet days; SDII: Simple daily intensity index; R20mm: Number of heavy precipitation days; R25mm: Number of very heavy precipitation days; CDD: Consecutive dry days; CWD: Consecutive wet days

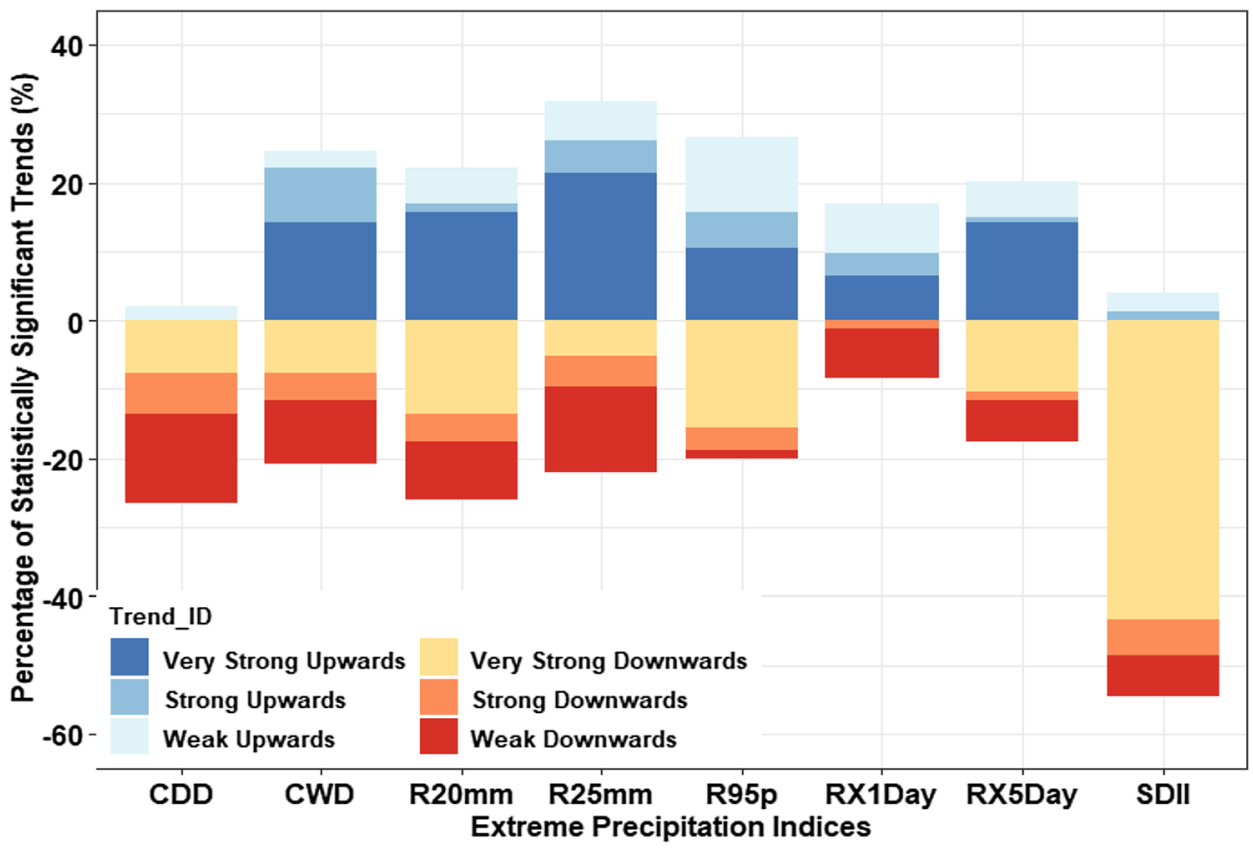

the central region. Moreover, stable upward trends (27$45 \%$ of the stations) were recorded more frequently than stable downtrends (9-27\% of the stations), except for SDII and CDD. Strongly and very strongly stable upward trends were regularly observed in the southern region (Can Gio and Tam Thon Hiep) for RX1day, RX5day, R95p, R25mm, and CWD, whereas CDD, R20mm, and SDII showed stable and strongly stable downtrends in these regions. Furthermore, $27 \%$ and $36 \%$ of the stations respectively presented strongly and very strongly stable downtrends in SDII, which covered most of the study area. On the contrary, most of the extreme precipitation indices expressed strongly and very strongly stable downtrends in the northern region, except for RX1day and CDD, which showed unstable trends according to their spatial patterns of trend strengths.

\subsubsection{Trend Magnitude in Extreme Precipitation Indices}

For CDD, the average magnitude of trends showed negative values in the entire study area, with the strongest decreasing rates of 1.2-2.3 days per year in the southern region (Tam Thon Hiep) and some areas in the center (Fig. 5). In the remaining regions ( $73 \%$ of the stations), the magnitude of the trends had decreasing rates of $0.1-$ 1.2 days per year.

In contrast, CWD presented an inverse spatial distribution of trend magnitude over the study area relative to CDD. The highest increasing rates of 0-0.2 day per year were mainly observed in the southern region and many parts of the central region, which corresponded to the stable and strong upward trends recorded in these regions.
Also CWD decreased at a rate of $0-0.1$ day per year in some parts of the northern and central regions of HCMC.

RX1day, RX5day, and R95p were quite similar in the spatial distribution of trend magnitudes, with an increasing gradient of magnitude values from the northwestern to southeastern sides. For RX1day, the average magnitude of trends had positive values in almost all regions (64\% of the stations) with increasing rates of 0-2 $\mathrm{mm}$ per year. RX5day had decreased mainly in the northern region at rates of $0.2-$ $1.8 \mathrm{~mm}$ per year. In contrast, the upward trends in RX5day were observed in most of the remaining regions (except for Tam Thon Hiep Station) with increasing trends of 0 $2.6 \mathrm{~mm}$ per year. For R95p, positive trends were observed in $64 \%$ of the stations with increasing trends of $1-16 \mathrm{~mm}$ per year. However, only $14 \%$ of these stations showed significantly and strongly stable upward trends; these are mainly located in the southern side of the city in the period 1980-2017.

For R20mm and R25mm, there were fewer differences in the spatial distribution of trends over the northern region and most parts in the central area; however, in the southern region of the study area, different spatial distributions were observed. Particularly, significant downtrends were found in the northern parts for both R20mm and R25mm with decreasing rates of 0.24 and 0.18 days per year, respectively. In the central and southern regions, both indices showed insignificantly increasing trends in most stations. For SDII, very strong and stable downtrends appeared over the study area. A negative magnitude of trends was found in $73 \%$ of the stations with rates of $0-0.4 \mathrm{~mm} /$ day per year. The highest decreasing velocity was observed at Cat Lai Station (at rates of over $0.37 \mathrm{~mm} /$ day per year). 
Table 2 Percentage of stations classified by different types of trend strengths and stability in Ho Chi Minh City during the period 19802017

\begin{tabular}{|c|c|c|c|c|c|c|c|c|c|}
\hline \multirow[b]{2}{*}{ Trend strengths } & \multirow[b]{2}{*}{$I T$} & \multicolumn{4}{|c|}{ Downwards (\%) } & \multicolumn{4}{|c|}{ Upwards (\%) } \\
\hline & & $w$ & & $s$ & $v s$ & & $w$ & $s$ & $v s$ \\
\hline RX1Day & 91 & 0 & & 0 & 0 & & 0 & 0 & 9 \\
\hline RX5Day & 73 & 0 & & 0 & 9 & & 0 & 0 & 18 \\
\hline SDII & 45 & 0 & & 0 & 55 & & 0 & 0 & 0 \\
\hline $\mathrm{R} 20 \mathrm{~mm}$ & 73 & 0 & 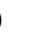 & 0 & 18 & & 0 & 0 & 9 \\
\hline $\mathrm{R} 25 \mathrm{~mm}$ & 45 & 18 & & 0 & 0 & & 9 & 0 & 27 \\
\hline CDD & 82 & 9 & 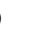 & 0 & 9 & & 0 & 0 & 0 \\
\hline CWD & 64 & 9 & 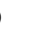 & 0 & 9 & & 0 & 9 & 9 \\
\hline R95p & 64 & 0 & 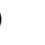 & 0 & 18 & & 9 & 0 & 9 \\
\hline \multirow[t]{2}{*}{$\%$ of stations in total } & 67 & 5 & 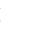 & 0 & 15 & & 2 & 1 & 10 \\
\hline & & \multicolumn{4}{|c|}{ Downwards } & \multicolumn{4}{|c|}{ Upwards } \\
\hline Trend stability & $U T$ & $P$ & $S$ & $S S$ & $V S S$ & $P$ & $S$ & $S S$ & $V S S$ \\
\hline RX1Day & 45 & 0 & 9 & 0 & 0 & 18 & 18 & 0 & 9 \\
\hline RX5Day & 27 & 0 & 0 & 9 & 9 & 0 & 18 & 9 & 9 \\
\hline SDII & 18 & 0 & 0 & 27 & 36 & 0 & 9 & 0 & 0 \\
\hline $\mathrm{R} 20 \mathrm{~mm}$ & 36 & 0 & 0 & 0 & 18 & 0 & 9 & 9 & 9 \\
\hline $\mathrm{R} 25 \mathrm{~mm}$ & 18 & 9 & 0 & 18 & 9 & 0 & 9 & 18 & 18 \\
\hline CDD & 55 & 9 & 0 & 9 & 9 & 0 & 0 & 0 & 0 \\
\hline CWD & 18 & 0 & 0 & 18 & 0 & 9 & 0 & 18 & 9 \\
\hline R95p & 18 & 0 & 0 & 9 & 9 & 18 & 18 & 9 & 9 \\
\hline$\%$ of stations in total & 34 & 3 & 1 & 13 & 13 & 6 & 12 & 9 & 9 \\
\hline
\end{tabular}

$I T$ insignificant trends; $w$ weak, $s$ strong, $v s$ very strong, UT unstable trends, $P$ poor, $S$ stable, $S S$ strongly stable, $V S S$ very strongly stable

RX1day: Max 1-day precipitation amount; RX5day: Max 5-day precipitation amount; R95p: Very wet days; SDII: Simple daily intensity index; R20mm: Number of heavy precipitation days; R25mm: Number of very heavy precipitation days; CDD: Consecutive dry days; CWD: Consecutive wet days

\subsection{Correlation Between Precipitation Extremes and Large-Scale Patterns of Atmospheric and Ocean Circulation}

The Pearson correlation coefficient was applied to calculate the relationship between the precipitation extreme indices in HCMC and large-scale patterns of atmospheric and ocean circulation, including global mean temperature, ENSO, and PDO in the period 1980-2017, and the results are presented in Table 3. The global mean temperature had a negative correlation with the duration of precipitation extremes (CDD and CWD) and a positive correlation with the intensity and frequency of the annual total precipitation (PRCPTOT) and precipitation extremes (R20mm, R25mm, R95p, RX1day, RX5day, and SDII). In contrast to the global mean temperature, ENSO and PDO had positive correlations with the duration of precipitation extremes and negative correlations with the intensity and frequency of precipitation extremes. However, most of the correlations were statistically insignificant, except for CDD. The results were almost identical to the findings of Limsakul and Singhruck (2016) and Tan et al. (2017), who reported negative correlations of precipitation extreme indices with ENSO and PDO in Thailand and Malaysia.

\subsection{Discussion}

Any changes in the climatic condition could cause risks to socioeconomic development or even disasters; thus, the spatiotemporal analysis of variability of rainfall and extreme rainfall events should be studied carefully to guide policymakers and planners. By analyzing long-term rainfall data, we found a higher rainfall intensity in the central region and significantly increasing trends were found in the northern and southern regions. The results of the trend analysis of annual rainfall in this study were consistent with findings by Phuong et al. (2019), who reported that increasing trends were dominant in most parts of the city. Additionally, Nguyen et al. (2014) indicated that annual rainfall had increasing trends in the period 1971-2010 in South Vietnam, including HCMC.

Climate change not only affects the occurrence and severity of flood but also drought events. We also found that in all stations, the $\mathrm{CV}$ values varied between 0.14 (Tan Son Hoa) and 0.35 (Can Gio) and showed very high variations in rainfall amounts and distribution patterns, indicating a serious potential of drought vulnerability over the city (Oscar Kisaka et al. 2015). If agricultural activities remain the same in the future in the northern part, further research regarding the assessment of drought possibility in the city would be highly recommended. In this study, the PCI results on an annual scale described a moderate precipitation concentration with an increasing gradient of irregularity from the northwestern (14.96) to the southeastern sides (18.25) of the city. The result could be used for studying drought and flood risks in the city and identifying potential drought-prone areas during the dry season.

For the analysis of average extreme precipitation indices on temporal and spatial scales, we used eight indices to consider three major characteristics of rainfall extremes, namely, intensity, duration, and frequency. In general, the frequency (R20mm and $\mathrm{R} 25 \mathrm{~mm}$ ) and intensity (RX1day, RX5day, and R95p) of extreme precipitation in HCMC had increasing trends in 1980-2017. However, the SDII value (ratio of annual rainfall to rainy days) showed a decreasing trend. This can be explained by the fact that the wet days significantly increased. In recent years, the shifting activity of tropical cyclones during September-November from the northward to the southward direction has occurred in 

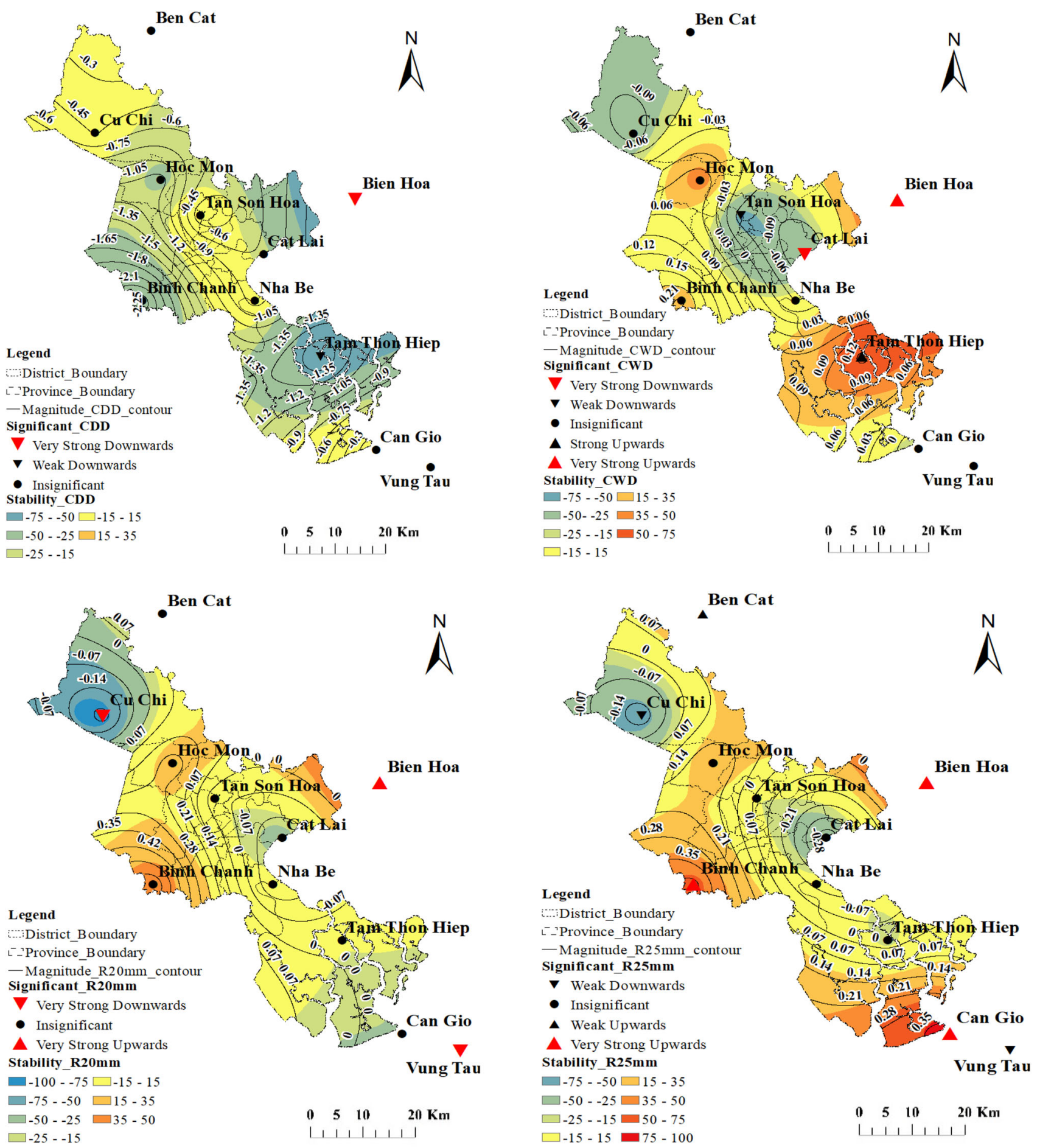

Fig. 5 Spatial distribution of the stability of trends in extreme precipitation indices, along with the corresponding trend strengths at each station in Ho Chi Minh City. The minus (-) symbols were used to denote the range value of the stability of downward trends. RX1day: Max 1-day precipitation amount; RX5day: Max 5-day

Vietnam (Darby et al. 2016). Thus, HCMC has been significantly affected by tropical cyclones. This may cause increases in the frequency and intensity of extreme

precipitation amount; R95p: Very wet days; SDII: Simple daily intensity index; R20mm: Number of heavy precipitation days; R25mm: Number of very heavy precipitation days; CDD: Consecutive dry days; CWD: Consecutive wet days

precipitation and wet days in HCMC. The increasing trends of intensity and frequency of extreme rainfall are in accordance with those observed in Singapore ( $\mathrm{Li}$ et al. 

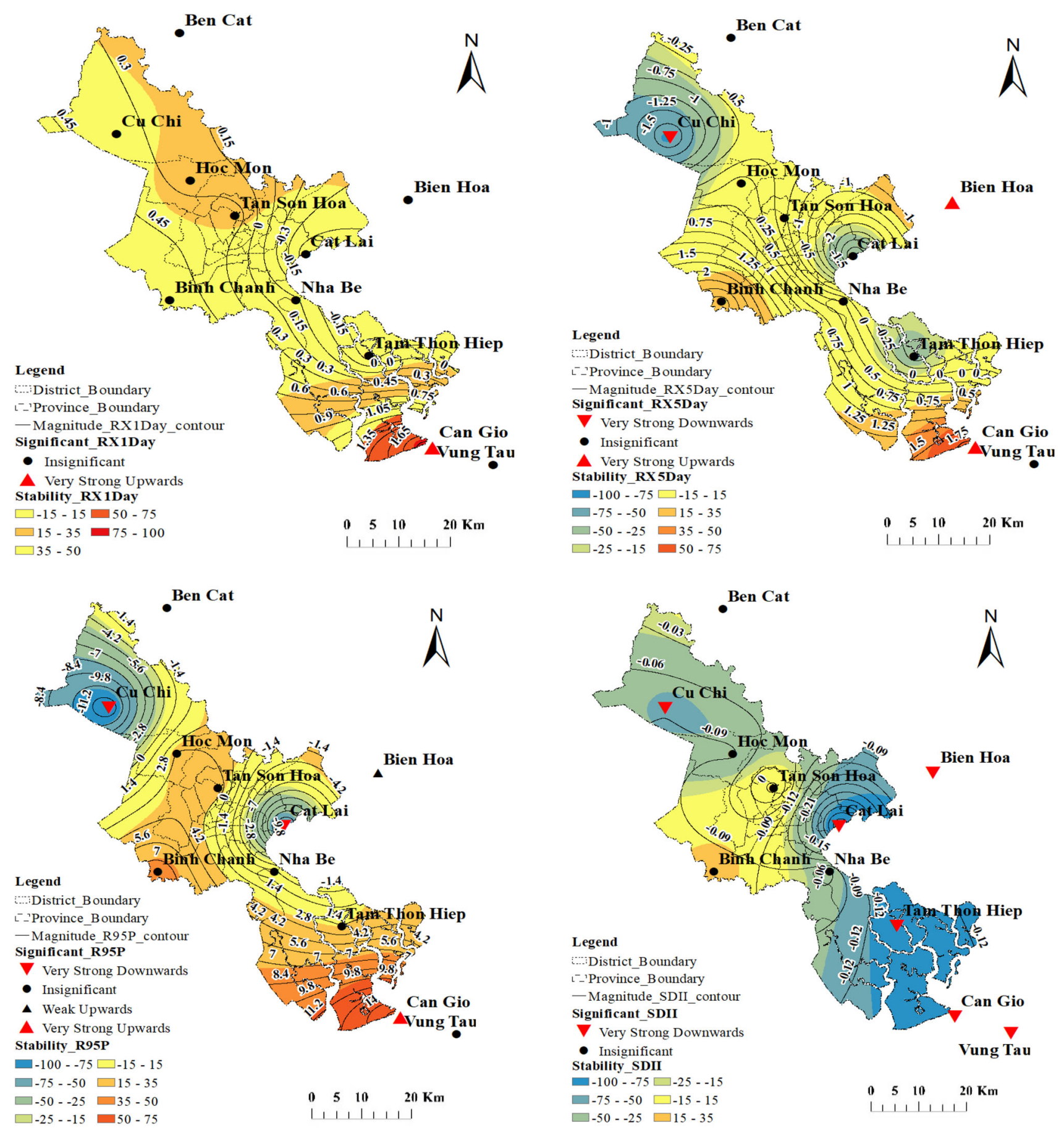

Fig. 5 continued

2018) and Muda River Basin (Malaysia) (Tan et al. 2019). In general, the rainfall extremes had increasing trends of intensity and frequency in Southeast Asia. Regarding the rainfall duration, CDD and CWD presented decreasing and increasing trends, respectively. The increasing trends of CWD and wet days are in agreement with a well-known finding by Kruk et al. (2015) that CWD is increasing in the wet regions. In another work, Khoi and Trang (2016) computed five extreme precipitation indices to investigate the changes in frequency, intensity, and duration of the extremes in HCMC during the period 1980-2013. Although the study only provided brief information about the spatial distribution of trends in extreme precipitation indices, which was primarily based on the magnitude of trends and did not consider the significance and stability of trends, the findings were consistent with our results in term 
Table 3 Correlation between global mean temperature (GMT), El Niño Southern Oscillation (ENSO), and Pacific Decadal Oscillation (PDO), and precipitation extreme indices in Ho Chi Minh City for the period 1980-2015

\begin{tabular}{lccccccrrrr}
\hline & CDD & CWD & R20mm & R25mm & R95p & RX1day & RX5day & SDII & PRCPTOT \\
\hline GMT & -0.09 & -0.3 & 0.35 & 0.26 & 0.32 & 0.17 & 0.28 & 0.31 & 0.26 \\
ENSO & $0.40^{*}$ & 0.14 & -0.28 & -0.32 & -0.28 & 0 & -0.16 & -0.12 & -0.37 \\
PDO & $0.51^{*}$ & 0.34 & -0.24 & -0.26 & -0.32 & -0.27 & -0.01 & -0.21 & -0.25 \\
\hline
\end{tabular}

*Significance level of 0.05

RX1day: Max 1-day precipitation amount; RX5day: Max 5-day precipitation amount; R95p: Very wet days; SDII: Simple daily intensity index; R20mm: Number of heavy precipitation days; R25mm: Number of very heavy precipitation days; CDD: Consecutive dry days; CWD: Consecutive wet days; PRCPTOT: annual total precipitation

of spatial distribution of trend magnitudes over the study area in the period 1980-2017.

The negative correlations of intensity and frequency of extreme rainfall and ENSO and PDO indicate that HCMC is prone to having higher amounts of rainfall and more extreme events during La Niña and PDO cool phase, and vice versa during El Niño and PDO warm phase. Duc et al. (2018) stated that ENSO has significant effects on rainfall in South Vietnam. Moreover, Nguyen-Thi et al. (2012) mentioned that ENSO (La Niña events) has strong effects on rainfall due to tropical cyclones in Vietnam. Generally, increasing impacts of ENSO and shifting in the tracks of tropical cyclones are possible reasons for increases in the frequency and intensity of extreme rainfall in recent years.

Recently, HCMC is facing a serious problem related to urban flooding due to high tides and heavy rainfalls. Thus, increasing intensity of rainfall and extreme rainfall would exacerbate this problem and cause adverse impacts on infrastructure and socioeconomic development in the city. Storch and Downes (2011) stated that the local government should take into consideration the increasing trends of rainfall and propose appropriate rainfall storage plans for flood risk management in HCMC. Furthermore, the increasing rainfall in the northern parts of the city could impose more potential threats to the reservoir in the upstream side of the city.

Previous studies reported that the underlying trends in climate extremes do not only depend on the long-term variability but also on the characteristics of seasonal distribution (Lupikasza 2010). Therefore, it is necessary to analyze and identify the linkage between the spatiotemporal variation in precipitation extremes and seasonality of precipitation, as well as the correlations in annual extreme precipitation indices.

\section{Conclusion}

In this study, we investigated the temporal and spatial variability of precipitation and extreme precipitation in HCMC during the period 1980-2017 through daily rainfall data analysis of 11 meteorological stations across the study area. The main conclusions can be summarized as follows: (1) The annual precipitation had uptrend in HCMC during 1980-2017, with high magnitudes found in the northern and southern areas of the city; (2) Regarding the extreme precipitation, the intensity and frequency of extreme precipitation had uptrends. In terms of the duration of extreme precipitation, CDD and CWD showed downtrend and uptrend, respectively; and (3) ENSO and PDO had a negative connection with the intensity and frequency of extreme precipitation and a positive connection with the duration of extreme precipitation in the period 1980-2017. Regarding the global mean temperature, it had a positive connection with the intensity and frequency of extreme precipitation and a negative connection with the duration of extreme precipitation.

The results of this study contribute to the analysis and assessment of the temporal and spatial variability of precipitation and extreme precipitation in the period 1980 2017. It can also provide a scientific reference for policymakers and city planners in developing, designing, and proposing the urban strategic development plans with integrated climate change mitigation and adaptation.

Acknowledgements This study was supported by the Science and Technology Incubator Youth Program, managed by the Center for Science and Technology Development, Ho Chi Minh Communist Youth Union (Contract Number 17/2018/HĐ-KHCN-VU'). It is also partly funded by Ho Chi Minh City's Department of Science and Technology (HCMC-DOST) and Institute for Computational Science and Technology (ICST) (Grant Number 05/2019/HĐ-KHCNTT).

Open Access This article is licensed under a Creative Commons Attribution 4.0 International License, which permits use, sharing, adaptation, distribution and reproduction in any medium or format, as long as you give appropriate credit to the original author(s) and the source, provide a link to the Creative Commons licence, and indicate if changes were made. The images or other third party material in this article are included in the article's Creative Commons licence, unless indicated otherwise in a credit line to the material. If material is not included in the article's Creative Commons licence and your intended use is not permitted by statutory regulation or exceeds the permitted use, you will need to obtain permission directly from the copyright holder. To view a copy of this licence, visit http://creativecommons. org/licenses/by/4.0/. 


\section{References}

Ahmad, I., F. Zhang, M. Tayyab, M.N. Anjum, M. Zaman, J. Liu, H. U. Farid, and Q. Saddique. 2018. Spatiotemporal analysis of precipitation variability in annual, seasonal and extreme values over upper Indus River Basin. Atmospheric Research 213: 346360.

Alexander, L.V. 2016. Global observed long-term changes in temperature and precipitation extremes: A review of progress and limitations in IPCC assessments and beyond. Weather and Climate Extremes 11: 4-16.

Alexander, L.V., X. Zhang, T.C. Peterson, J. Caesar, B. Gleason, A. M.G. Klein Tank, M. Haylock, D. Collins, et al. 2006. Global observed changes in daily climate extremes of temperature and precipitation. Journal of Geophysical Research 111(D5): Article D05109.

Barrett, C.B., and P. Santos. 2014. The impact of changing rainfall variability on resource-dependent wealth dynamics. Ecological Economics 105: 48-54.

Binh, L.T.H., N.V. Umamahesh, and E.V. Rathnam. 2019. Highresolution flood hazard mapping based on nonstationary frequency analysis: Case study of Ho Chi Minh City, Vietnam. Hydrological Sciences Journal 64(3): 318-335.

Cooper, R.T. 2019. Projection of future precipitation extremes across the Bangkok Metropolitan Region. Heliyon 5(5): Article e01678.

D'Arrigo, R., and C.C. Ummenhofer. 2015. The climate of Myanmar: Evidence for effects of the Pacific decadal oscillation. International Journal of Climatology 35(4): 634-640.

Darby, S.E., C.R. Hackney, J. Leyland, M. Kummu, H. Lauri, D.R. Parsons, J.L. Best, A.P. Nicholas, and R. Aalto. 2016. Fluvial sediment supply to a mega-delta reduced by shifting tropicalcyclone activity. Nature 539(7628): 276-279.

Donat, M.G., A.L. Lowry, L.V. Alexander, P.A. O'Gorman, and N. Maher. 2016. More extreme precipitation in the world's dry and wet regions. Nature Climate Change 6: 508-513.

Duc, H.N., H.Q. Bang, and N.X. Quang. 2018. Influence of the Pacific and Indian Ocean climate drivers on the rainfall in Vietnam. International Journal of Climatology 38(15): 5717-5732.

Eckstein, D., V. Künzel, and L. Schäfer. 2017. Global climate risk index 2018: Who suffers most from extreme weather events? Weather-related loss events in 2016 and 1997 to 2016. Bonn, Germany: Germanwatch e.V. https://germanwatch.org/sites/ger manwatch.org/files/publication/20432.pdf. Accessed 15 Sept 2018.

Endo, N., J. Matsumoto, and T. Lwin. 2009. Trends in precipitation extremes over Southeast Asia. SOLA 5(1): 168-171.

Field, C.B., V. Barros, T.F. Stocker, and D. Qin (eds.). 2012. Managing the risks of extreme events and disasters to advance climate change adaptation. Cambridge: Cambridge University Press.

Gobin, A., H.T. Nguyen, V.Q. Pham, and H.T.T. Pham. 2016. Heavy rainfall patterns in Vietnam and their relation with ENSO cycles. International Journal of Climatology 36(4): 1686-1699.

Gocic, M., and S. Trajkovic. 2013. Analysis of changes in meteorological variables using Mann-Kendall and Sen's slope estimator statistical tests in Serbia. Global and Planetary Change 100: 172-182.

Guan, K., S.P. Good, K.K. Caylor, H. Sato, E.F. Wood, and H. Li. 2014. Continental-scale impacts of intra-seasonal rainfall variability on simulated ecosystem responses in Africa. Biogeosciences 11(23): 6939-6954.

Hadi, S.J., and M. Tombul. 2018. Comparison of spatial interpolation methods of precipitation and temperature using multiple integration periods. Journal of the Indian Society of Remote Sensing 46: 1187-1199.
Hamed, K.H. 2009. Enhancing the effectiveness of prewhitening in trend analysis of hydrologic data. Journal of Hydrology 368(14): 143-155.

HCMC-SO (Ho Chi Minh City Statistical Office). 2017. Ho Chi Minh City statistical yearbook 2016. Ho Chi Minh City, Vietnam: Thanh Nien Publishing House.

Ho, T., V. Phan, N. Le, and Q. Nguyen. 2011. Extreme climatic events over Vietnam from observational data and RegCM3 projections. Climate Research 49(2): 87-100.

IMHEN and UNDP (Institute of Meteorology, Hydrology and Environment, and United Nations Development Programme). 2015. Summary for policymakers. Viet Nam special report on managing the risks of extreme events and disasters to advance climate change adaptation. Hanoi, Vietnam: Natural Resources and Environment Publishing House. https://www.undp.org/con tent/dam/vietnam/docs/Publications/Final\%20Full\%20SPM\% 20SREX\%20in\%20English.pdf. Accessed 15 Sept 2018.

IPCC (Intergovernmental Panel on Climate Change). 2013. Summary for policymakers. Climate change 2013-The physical science basis. Cambridge, UK: Cambridge University Press.

Karl, T.R., N. Nicholls, and A. Ghazi. 1999. CLIVAR/GCOS/WMO workshop on indices and indicators for climate extremes workshop summary. In Weather and climate extremes, ed. T.R. Karl, N. Nicholls, and A. Ghazi, 3-7. Dordrecht: Springer.

Kendall, M.G. 1955. Further contributions to the theory of paired comparisons. Biometrics 11(1): Article 43.

Khoi, D.N., and H.T. Trang. 2016. Analysis of changes in precipitation and extremes events in Ho Chi Minh City, Vietnam. Procedia Engineering 142: 228-234.

Kruk, M.C., A.M. Lorrey, G.M. Griffiths, M. Lander, E.J. Gibney, H. J. Diamond, and J.J. Marra. 2015. On the state of the knowledge of rainfall extremes in the western and northern Pacific basin. International Journal of Climatology 35(3): 321-336.

Li, X., X. Wang, and V. Babovic. 2018. Analysis of variability and trends of precipitation extremes in Singapore during 1980-2013. International Journal of Climatology 38(1): 125-141.

Limsakul, A., and P. Singhruck. 2016. Long-term trends and variability of total and extreme precipitation in Thailand. Atmospheric Research 169(A): 301-317.

Lupikasza, E. 2010. Spatial and temporal variability of extreme precipitation in Poland in the period 1951-2006. International Journal of Climatology 30(7): 991-1007.

Mann, H.B. 1945. Nonparametric tests against trend. Econometrica 13 (3): Article 245.

Mei, C., J. Liu, M.-T. Chen, H. Wang, M. Li, and Y. Yu. 2018. Multidecadal spatial and temporal changes of extreme precipitation patterns in northern China (Jing-Jin-Ji district, 1960-2013). Quaternary International 476: 1-13.

Ngo-Duc, T. 2014. Climate change in the coastal regions of Vietnam. In Coastal disasters and climate change in Vietnam, ed. N.D. Thoa, H. Takagi, and M. Esteban, 173-198. London: Elsevier.

Nguyen, D.-Q., J. Renwick, and J. McGregor. 2014. Variations of surface temperature and rainfall in Vietnam from 1971 to 2010. International Journal of Climatology 34(1): 249-264.

Nguyen-Thi, H.A., J. Matsumoto, T. Ngo-Duc, and N. Endo. 2012. A climatological study of tropical cyclone rainfall in Vietnam. SOLA 8(1): 41-44.

Oliver, J.E. 1980. Monthly precipitation distribution: A comparative index. The Professional Geographer 32(3): 300-309.

Oscar Kisaka, M., M. Mucheru-Muna, F. Ngetich, J. Mugwe, D. Mugendi, and F. Mairura. 2015. Seasonal rainfall variability and drought characterization: Case of eastern arid region, Kenya. In Adapting African agriculture to climate change, ed. W. Leal Filho, A. Esilaba, K. Rao, and G. Sridhar, 53-71. Berlin: Springer. 
Peterson, T.C., C. Folland, G. Gruza, H. William, A. Mokssit, and N. Plummer. 2001. Report on the activities of the working group on climate change detection and related Rapporteurs 1998-2001. http://etccdi.pacificclimate.org/docs/wgccd.2001.pdf. Accessed 15 Sept 2018.

Phuong, D.N.D., V.T. Linh, T.T. Nhat, H.M. Dung, and N.K. Loi. 2019. Spatiotemporal variability of annual and seasonal rainfall time series in Ho Chi Minh City, Vietnam. Journal of Water and Climate Change 10(3): 658-670.

Pińskwar, I., A. Choryński, D. Graczyk, and Z.W. Kundzewicz. 2019. Observed changes in extreme precipitation in Poland: 19912015 versus 1961-1990. Theoretical and Applied Climatology 135: 773-787.

Revadekar, J.V., and B. Preethi. 2012. Statistical analysis of the relationship between summer monsoon precipitation extremes and food grain yield over India. International Journal of Climatology 32(3): 419-429.

Rosenzweig, C., F.N. Tubiello, R. Goldberg, E. Mills, and J. Bloomfield. 2002. Increased crop damage in the US from excess precipitation under climate change. Global Environmental Change 12(3): 197-202.

Sen, P.K. 1968. Robustness of some nonparametric procedures in linear models. The Annals of Mathematical Statistics 39(6): 1913-1922.

Sharma, D., and M.S. Babel. 2014. Trends in extreme rainfall and temperature indices in the western Thailand. International Journal of Climatology 34(7): 2393-2407.

Sheikh, M.M., N. Manzoor, J. Ashraf, M. Adnan, D. Collins, S. Hameed, M.J. Manton, A.U. Ahmed, et al. 2015. Trends in extreme daily rainfall and temperature indices over South Asia. International Journal of Climatology 35(7): 1625-1637.

Storch, H., and N.K. Downes. 2011. A scenario-based approach to assess Ho Chi Minh City's urban development strategies against the impact of climate change. Cities 28(6): 517-526.

Supari, F.T., L. Juneng, and E. Aldrian. 2017. Observed changes in extreme temperature and precipitation over Indonesia. International Journal of Climatology 37(4): 1979-1997.

Tan, M.L., A.L. Ibrahim, A.P. Cracknell, and Z. Yusop. 2017. Changes in precipitation extremes over the Kelantan River Basin, Malaysia. International Journal of Climatology 37(1): 3780-3797.

Tan, M.L., N. Samat, N.W. Chan, A.J. Lee, and C. Li. 2019. Analysis of precipitation and temperature extremes over the Muda River Basin, Malaysia. Water 11(2): Article 283.

Tian, J., J. Liu, J. Wang, C. Li, H. Nie, and F. Yu. 2017. Trend analysis of temperature and precipitation extremes in major grain producing area of China. International Journal of Climatology 37 (2): $672-687$.
UN (United Nations). 2014. Migration, resettlement and climate change in Viet Nam: Reducing exposure and vulnerabilities to climatic extremes and stresses through spontaneous and guided migration. Hanoi, Vietnam: United Nations Vietnam. https://www.undp.org/ content/dam/vietnam/docs/Publications/Migration\%20\&\%20Cli mate\%20change\%20-\%20Eng.pdf. Accessed 15 Sept 2018.

van den Besselaar, E.J.M., A.M.G. Klein Tank, and T.A. Buishand. 2013. Trends in European precipitation extremes over 19512010. International Journal of Climatology 33(12): 2682-2689.

van Leeuwen, C.J, N.P. Dan, and C. Dieperink. 2016. The challenges of water governance in Ho Chi Minh City. Integrated Environmental Assessment and Management 12(2): 345-352.

von Storch, H. 1995. Misuses of statistical analysis in climate research. In Analysis of climate variability, ed. H. von Storch, and A. Navarra, 11-26. Berlin: Springer.

Wang, X.L., and Y. Feng. 2004. RClimDex (1.0): User manual. Toronto, Canada: Climate Research Division, Atmospheric Science and Technology Directorate, Science and Technology Branch, Environment Canada. https://acmad.net/rcc/procedure/ RClimDexUserManual.pdf. Accessed 15 Aug 2018.

Wang, X.L., and Y. Feng. 2013. RHtestsV4: User manual. Toronto, Canada: Climate Research Division, Atmospheric Science and Technology Directorate, Science and Technology Branch, Environment Canada. http://etccdi.pacificclimate.org/RHtest/ RHtestsV4_UserManual_10Dec2014.pdf. Accessed 15 Aug 2018.

Wang, X., X. Hou, and Y. Wang. 2017. Spatiotemporal variations and regional differences of extreme precipitation events in the coastal area of China from 1961 to 2014. Atmospheric Research 197: 94-104.

Wang, X., G. Huang, and J. Liu. 2016. Observed regional climatic changes over Ontario, Canada, in response to global warming. Meteorological Applications 23(1): 140-149.

WB (World Bank). 2010. Climate risks and adaptation in Asian coastal megacities: A synthesis report. Washington, DC: World Bank. http://documents.worldbank.org/curated/en/ 866821468339644916/pdf/571100WP0REPLA1egaci ties01019110web.pdf. Accessed 15 Sept 2018.

WEF (World Economic Forum). 2018. The global risks report 2018. Geneva: World Economic Forum. http://www3.weforum.org/ docs/WEF_GRR18_Report.pdf. Accessed 10 Oct 2018.

Wu, C.H., G.R. Huang, H.J. Yu, Z.Q. Chen, and J.G. Ma. 2014. Spatial and temporal distributions of trends in climate extremes of the Feilaixia catchment in the upstream area of the Beijiang River Basin, South China. International Journal of Climatology 34(11): 3161-3178.

Zhang, Y., G. Huang, X. Wang, and Z. Liu. 2017. Observed changes in temperature extremes for the Beijing-Tianjin-Hebei region of China. Meteorological Applications 24(1): 74-83. 